\title{
A vida sentimental das mercadorias: a estética da "fofura" e seus jogos de poder na arte de Jeff Koons
}

Pedro Pinheiro Neves

I - UFRJ

Rio de Janeiro (RJ), Brasil

Resumo: Este artigo analisa algumas obras do artista Jeff Koons fazendo uso da categoria estética vernacular cute (fofo, adorável em inglês). Em suas esculturas representando bichinhos e brinquedos, Koons dá expressão formal para as contradições e ambiguidades do cute, de forma a explicitar os sentimentos ambivalentes e anseios que lastreiam a relação dos sujeitos consumidores-espectadores do capitalismo tardio com as mercadorias que os circundam. Pensar a mercadoria e o consumo - cultural, inclusive - a partir da estética da fofura nos ajuda, argumentamos, a melhor entender o próprio lugar da arte em um circuito globalizado e crescentemente dominado pela lógica mercadológica neoliberal. A obra de Koons, um dos artistas contemporâneos mais populares e financeiramente bem-sucedidos, é local privilegiado para observar as oscilações de poder no campo das artes visuais.

Palavras-Chave: artes visuais; estética; mercadoria; Jeff Koons.

Abstract: The sentimental life of commodities: the aesthetics of cuteness and its play of power in the art of Jeff Koons - The present paper analyzes a few works by artist Jeff Koons using the vernacular aesthetic category cute. In his sculptures representing critters and toys, Koons gives formal expression to the contradictions and ambiguities of cuteness, making explicit the ambivalent feelings and longings that underpin the relationship between the consumerspectators of late capitalism and the commodities that surround them. Reflecting on commodities and consumption - cultural consumption included - in light of the aesthetics of cuteness helps us, or so we argue, to better understand the very place of art in a globalized circuit increasingly dominated by neoliberal market logic. The work of Koons, one of the most popular and financially successful contemporary artists, is a privileged vantage point from which to observe power shifts in the field of visual arts.

Keywords: visual arts; aesthetics; commodity; Jeff Koons. 
Ao longo de sua carreira, o artista americano Jeff Koons (1955 -) tem se dedicado a investigar algo que podemos chamar de uma estética da mercadoria - as múltiplas formas em que as qualidades materiais e sensoriais dos objetos que nos circundam na paisagem urbana suscitam respostas estéticas e emocionais nos cidadãos-consumidores por eles interpelados. A centralidade da mercadoria na obra de Jeff Koons nos permite refletir sobre a ambígua relação entre ela e a obra de arte e, talvez de forma ainda mais incisiva, sobre a relação da mercadoria conosco, os consumidores de produtos e fenômenos estéticos do capitalismo contemporâneo.

Koons ocupa o posto de artista mais emblemático da expansão global, aumento vertiginoso de preços e cobertura midiática espetacular do campo das artes visuais. Ele inicia sua carreira no começo dos anos 1980, como expoente de um grupo de artistas trabalhando com o que o crítico Hal Foster chama de "pintura simulacionista" e "escultura de bens de consumo" (FOSTER, 2001, p.101-126). Para Foster, artistas como Koons, Haim Steinbach e Peter Halley representavam "a arte da razão cínica" (Ibidem, p. 118), empregando métodos críticos e desconstrutivistas já desenvolvidos pelas neovanguardas de forma descompromissada, irônica e, no limite, niilista. Com seus aspiradores de pó em caixas de acrílico, Koons referenciava o readymade de Duchamp e o consumismo da sociedade capitalista tardia, mas com tal fascínio fetichista pelas superfícies brilhantes e coloridas que a crítica se tornaria indistinguível da cumplicidade, e as estruturas da arte como mercadoria, e da mercadoria como símbolo de status, permaneceriam inalteradas (Ibidem, p. 114).

É importante ressaltar as diferenças entre a prática artística de Koons e a de alguns dos seus predecessores. Se a operação de deslocar objetos banais de seus contextos cotidianos para o espaço legitimado do museu se origina em Duchamp, a diferença é que, em Koons, esses objetos não são meramente utilitários como urinóis e escorredores de garrafas, mas são, desde o princípio, artefatos criados com uma intenção estética, tendo já daí algum parentesco com a arte - seus filhos bastardos que retornam para usurpar o trono. No que se refere à pop art, a diferença principal diz respeito aos formatos em que se efetiva essa passagem do banal à arte. Os artistas pop levavam a linguagem dos quadrinhos e anúncios publicitários ao meio já estabelecido da pintura; no caso de Koons, não há transcendência do vulgar através de novos materiais: eles permanecem incorporados em porcelana pintada, madeira policromada e aço inox e, muitas vezes, fabricados pelos mesmos artesãos que têm na confecção de bibelôs kitsch o seu ofício.

Os artistas da commodity sculpture estariam, para Foster, jogando o "jogo final da arte" (FOSTER, 2001, p. 109), um termo que ecoa os escritos de Arthur Danto sobre a arte depois do modernismo. Para o filósofo, com as caixas Brillo, de Warhol (1964), a arte haveria cumprido seu destino de se tornar filosoficamente autoconsciente, encerrando assim a narrativa moderna de avanços sucessivos rumo ao progresso.

Qualquer arte que houvesse depois seria feita sem o benefício de uma narrativa tranquilizadora na qual ela seria vista como o próximo estágio correto na história. O que havia chegado ao fim era esta narrativa, mas não o sujeito da narrativa. (DANTO, 1997, p. 4) 
A produção artística contemporânea, portanto, gozaria das incertezas e da liberdade de uma condição pós-histórica, na qual "a arte do passado está disponível para o uso que os artistas quiserem dar a ela" (Ibidem, p. 5), todo um arsenal de técnicas e estilos libertos de significado para serem combinados livremente. Sem a pressão de um destino histórico a ser cumprido, a arte haveria se tornado um jogo trivial.

Para Foster, essa narrativa do fim da narrativa coincide, incomodamente, com a ascensão das políticas econômicas neoliberais e a consequente abertura mundial de mercados que ela proporciona:

Este "fim da arte" é apresentado como benignamente liberal - a arte é pluralista, sua prática pragmática e seu campo, multicultural - mas esta posição é também não-tão-benignamente neoliberal, no sentido de que o seu relativismo é o que a lei do mercado requer. (FOSTER, 2002, p 125)

O pluralismo contemporâneo, portanto, seria o signo de uma crescente submissão das artes visuais à lógica mercadológica.

Essa nova situação do campo das artes precisa ser compreendida dentro de uma moldura que dê conta das transformações no status tanto da obra de arte quanto da mercadoria; para tanto, acreditamos ser útil nos voltarmos aos estudos da estética. Os modelos dominantes da teoria estética, calcados como estão nas categorias do belo e do sublime, frequentemente presumem a experiência estética como espaço de exceção dentro do fluxo ordinário da vida, experiências de arrebatamento que compelem a nossa atenção e nossos sentidos e que nos põem em contato com correntes de sensibilidade aguda que permanecem adormecidas em nosso trato cotidiano com os objetos e fenômenos à nossa volta. Se aceitamos, entretanto, o diagnóstico feito por Jameson da situação expandida da esfera cultural no Ocidente do capitalismo tardio, temos que admitir que o encontro com objetos e fenômenos que interpelam insistentemente nossos sentidos exigindo respostas estéticas tornou-se corriqueiro, pondo em xeque a própria noção da autonomia da esfera da estética.

O espaço fechado da estética é [...] a partir de então totalmente culturalizado; [...] onde a esfera da cultura se expande a ponto de que tudo se torna, de um jeito ou de outro, aculturado, a distinção ou a "especificidade" tradicional da estética (e até mesmo da cultura como tal) é necessariamente esvaecida ou totalmente perdida. (JAMESON, 2006, p. 183).

Faz-se necessário, portanto, reunir ferramentas para lidar com esse campo expandido da experiência estética que se espraia via design, publicidade, meios de comunicação massivos, arquitetura e redes sociais. As categorias estéticas vernaculares - marcadas pela trivialidade e inconsequência (NGAI, 2102, p. 18), bem como por sua íntima ligação com as culturas de consumo - são instrumentos úteis para pensar nossas relações afetivas com a esfera mercantilizada da experiência no capitalismo tardio. 
A ideia de um subgrupo de categorias estéticas "menores" parece notavelmente saliente para o relato histórico da ascensão de estéticas do consumo. (...) O que essas categorias estéticas baseadas em sentimentos mais brandos ou equívocos tornam explícita, de uma maneira que categorias baseadas em sentimentos poderosos evocados por experiências raras de arte e natureza não conseguem, é a continuidade e cotidianidade de nossa relação estética com as mercadorias projetadas [designed], embaladas e anunciadas de forma frequentemente artística que nos cercam em nossos lares, lugares de trabalho e nas ruas. (Ibidem, p. 58)

Neste artigo, analisamos algumas esculturas de Koons representando bichinhos ou brinquedos infantis. Ao refletir sobre essas obras, o conceito de cute (fofo, adorável em inglês), pensado como uma categoria estética vernacular, será uma das nossas pedras de toque. Por meio de sua investigação formal acerca de objetos banais e açucarados da cultura de massa, o artista mobiliza o antigo tropo marxiano da animação da mercadoria sob o sistema capitalista, de forma a refletir sobre o próprio lugar paradoxal da arte na atualidade.

\section{A vida superior das mercadorias}

Como forma de ilustrar a estranha condição assumida pelos objetos ao tornarem-se mercadorias, Karl Marx utiliza-se, em o O Capital, da imagem de uma mesa que ganha vida:

[A] forma da madeira é alterada quando dela se faz uma mesa. No entanto, a mesa continua sendo madeira, uma coisa sensível e banal. Mas tão logo aparece como mercadoria, ela se transforma numa coisa sensível-suprassensível. Ela não só se mantém com os pés no chão, mas põe-se de cabeça para baixo diante de todas as outras mercadorias, e em sua cabeça de madeira nascem minhocas que nos assombram muito mais do que se ela começasse a dançar por vontade própria. (MARX, 2013, p. 116)

O caráter quase-vivo da mercadoria capitalista dá-se, para Marx, graças ao ocultamento das condições de produção que Ihe são subjacentes. Reificado o humano, abstraído como força de trabalho, a mercadoria produzida em decorrência de relações sociais concretas aparece como um dado natural, autogerado e autônomo.

Tomados em conjunto, os tropos da reificação do humano e da animação do inorgânico apontam para uma sensação de insegurança e perda de controle da parte dos sujeitos sob a égide do capital que percebem suas vidas governadas por forças que, apesar de engendradas pela humanidade, adquirem uma agência própria. Enquanto os seres humanos são sujeitados por uma rotina massacrante e exploradora ou lutam para performar como uma máquina e exibir-se como um produto, as mercadorias parecem gozar de uma vida superior, caracterizada por uma invejável mobilidade, efeito da sua identidade instável como valor abstrato. Enquanto muitas pessoas são obrigadas a poupar, privando-se de consumir prazeres e experiências, o dinheiro - a mercadoria por 
excelência - tem livre passe para circular pelos espaços em que esses mesmos prazeres e experiências são vendidos: "tudo o que você é incapaz de fazer, o seu dinheiro pode fazer por você: ele pode comer, beber, sair para dançar, ir ao teatro; pode adquirir arte, educação, curiosidades históricas, poder político, ele pode viajar, ele é capaz de fazer todas essas coisas por você" (MARX, 1992, p. 361).

A vida superior das mercadorias, acessada apenas de forma vicária pelos humanos que as fabricam, ganha uma interessante expressão em um conto de fadas, inventado por Marx para entreter as suas filhas, no qual brinquedos dotados de subjetividade e de uma vida plena e excitante viajam o mundo em aventuras enquanto o seu criador, endividado, permanece imóvel e impotente em sua loja. Segundo relata Eleanor Marx:

Hans Röckle era um mágico [...] que tinha uma loja de brinquedos e que estava sempre "duro". Sua loja estava cheia das coisas mais maravilhosas - homens e mulheres de madeira, gigantes e anões, reis e rainhas, servos e mestres, animais e pássaros tão numerosos quanto os que entraram na Arca de Noé [...]. Embora ele fosse um mágico, Hans nunca conseguia cumprir suas obrigações seja para com o demônio, seja para com o açougueiro, e era portanto - muito contra a sua vontade - constantemente obrigado a vender seus brinquedos para o diabo. Esses brinquedos passavam, pois, por maravilhosas aventuras, terminando, sempre, por retornar à loja de Hans Röckle. (MARX apud STALLYBRASS, 2000, p. 95-96)

O uso de brinquedos, por Marx, para ilustrar de forma fabular a alienação do trabalhador em relação aos produtos dos seus trabalhos é condizente com o significado original da palavra fetiche, que viria a ocupar um lugar central em seu léxico. Derivado de feitiço, o termo surgiu primeiro no século 16 entre mercadores portugueses e era usado para "demonizar o apego supostamente arbitrário dos africanos ocidentais aos objetos materiais" (STALLYBRASS, 2000, p. 57). No século 18, o termo, ainda carregado de conotações racistas, é adotado pela nascente disciplina da antropologia para referir-se a práticas religiosas africanas associadas à "idolatria" e às superstições do antigo Egito (AGAMBEN, 1993, p. 33). Os supostos fetiches dos antropólogos franceses tomavam a forma de estatuetas e miniaturas, ancestrais dos modernos brinquedos. De fato, segundo o historiador Philippe Ariès (1962, p. 69-70), a barreira que separa brinquedos e artefatos religiosos - como ex-votos, oferendas e miniaturas funerárias - não era bem definida no mundo antigo, enquanto que nos séculos 18 e 19 a dificuldade do historiador estaria em distinguir joguetes infantis de bibelôs e objetos decorativos destinados a adultos.

A relação da criança com o brinquedo - particularmente com brinquedos antropomórficos, como bonecos e pelúcias - é fetichista, na medida em que ela enxerga no objeto inanimado um componente imaterial: uma alma. É na boneca que a criança investe seus afetos, seu amor e seu cuidado. Mas essa relação é marcada pela frustração, já que esse amor é impossível de ser retribuído. Maleáveis, manipuláveis e sempre disponíveis aos nossos abraços, os brinquedos permanecem impenetráveis e inacessíveis. 
Se encontrássemos [...] uma dessas bonecas [...] ela quase nos daria raiva com sua assustadora e grossa desatenção, o ódio, que, sem dúvida, sempre constituiu uma parte da nossa relação inconsciente com ela, irromperia, e ela jazeria diante de nós desmascarada como o estranho e horrível corpo sobre o qual dissipamos nossa mais pura ternura; [...] Não somos nós criaturas estranhas, por nos permitirmos ser induzidos a dispor nossas primeiras afeições onde elas permanecem privadas de esperança? (RILKE, 1978, p.46-47)

\section{Os jogos de poder do cute}

Nosso relacionamento infantil com os brinquedos prefigura a futura relação com a mercadoria: um misto de desejo, esperança, amor, possessividade, frustração, raiva e dependência. E é na mais infantilizada das categorias estéticas que a teórica Sianne Ngai (2012) identifica uma semelhança estrutural com a nossa relação com a mercadoria: o cute ${ }^{1}$.

O cute, como categoria vernacular e "fraca", não se baseia em um sentimento inequívoco e poderoso, mas caracteriza-se pela mobilização de sentimentos ambivalentes e conflitantes. A principal característica formal de objetos considerados cute é um aspecto geral informe, não plenamente desenvolvido - precisamente a característica que nos atrai em bebês humanos, com suas cabeças e olhos grandes, membros curtos e corpo mole e macio (NGAI, 2012, p. 24). É uma estética baseada no reconhecimento de "atributos humanos em coisas não humanas" (HARRIS, 2000, p. 11), sejam elas filhotes de animais, brinquedos ou objetos inanimados dos mais variados. Esse reconhecimento, entretanto, deve ser deficiente: humano, mas não demasiadamente humano, ou entramos no reino assustador do estranho, do unheimlich freudiano (NGAI, 2012, p. 91). Ou, em outras palavras, humano o suficiente para despertar nossa empatia, mas não a ponto de representar uma possível ameaça.

Em seu aspecto malformado, o cute aproxima-se, portanto, do grotesco, e por isso o encanto que provoca é matizado por algo de repulsa. "O grotesco é cute porque o grotesco dá pena, e pena é a emoção primária dessa estética sedutora e manipuladora que desperta nossa simpatia através da criação de párias anatômicos." (HARRIS, 2000, p. 4) A interseção entre o cute e o grotesco é um campo fértil para Koons, que a explorou em diversas esculturas da série Banality, produzida no final dos anos 1980. É o caso, por exemplo, de Popples (1988) (Fig. 1). Suas pernas inchadas são tocos sem dedos; seus braços, abertos como se implorando nosso abraço, terminam em patas desprovidas da capacidade de executar qualquer função. Seu corpo é uma bola amorfa, suas bochechas inchadas contrastam com o focinho achatado e seu olhar choroso é estúpido e vazio. Sem alterar significativamente o modelo original que o inspirou, Koons, entretanto, exagera as características mais repulsivas da criatura, inspirando mais aversão que um desejo de acolhimento.

1 A tradução mais certeira de cute, baseando-nos no uso coloquial da palavra, seria "fofo"; entretanto, para evitar confusão com a propriedade material que a palavra portuguesa designa, relacionada com maciez e maleabilidade, optamos por manter o termo em inglês neste artigo. 


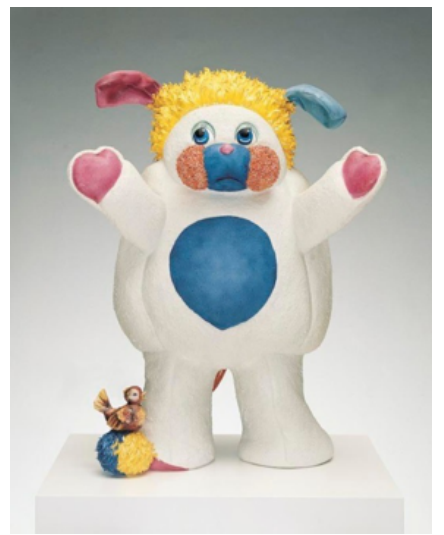

Fig.1. Popples (1988) Fonte: jeffkoons.com

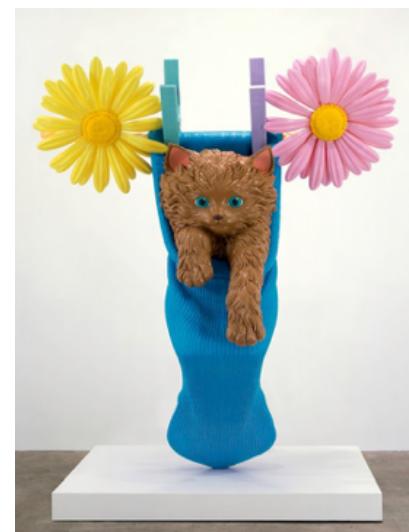

Fig.2. Cat on a clothesline (1994-2001) Fonte: jeffkoons.com

Em outras obras, Koons põe em relevo outra característica essencial do cute: o desamparo, aquilo que nos impele a proteger e cuidar do que nos parece fofinho. Na escultura de polietileno Cat on a clothesline (1994-2001), da série Celebration, um gatinho está preso em uma meia pendurada no varal, incapaz de descer sem ajuda (Fig. 2).

O cute solicita um olhar à mercadoria como um ser antropomórfico menos poderoso que o sujeito estético, apelando especificamente a nós por proteção e cuidado. Nas palavras de [Lori] Merish, o cute "em certo sentido sempre designa uma mercadoria em busca da sua mãe", assim "enxertando o desejo da mercadoria em uma estrutura de classe-média de emoção familial ou expressamente maternal." (NGAI, 2012, p. 60)

O cute, portanto, é baseado em uma assimetria de poder entre um sujeito estético poderoso e um objeto indefeso e necessitado de cuidados. O prazer causado pelo cute depende da manutenção dessa assimetria, o que explica o componente sádico de qualquer relação com o que é cute: é necessário manter ou mesmo ampliar a situação de desamparo e dependência do objeto em relação ao sujeito. O objeto cute desperta nosso desejo de abraçá-lo, beijá-lo e apertá-lo a ponto do sufocamento, ou de mordê-lo e engoli-lo, provando que a nossa capacidade de proteção e carinho pode facilmente transformar-se em poder de mutilar e destruir - os dois impulsos nunca estão muito distantes. Nosso completo domínio sobre o objeto cute nos permite dispor do seu corpo a nosso bel prazer; ele é fisicamente incapaz de retribuir nossos mais violentos apertos. Sobre bichos de pelúcia, Harris afirma: "animais como estes habitam um mundo de tranquilizante imediatez tátil no qual não existem quinas agudas ou materiais abrasivos, mas no qual todas as arestas foram convenientemente arredondadas para ceder aos nossos importunos apertos e abraços" (2000, p. 8). É a ausência dessa maciez e maleabilidade que provoca 
estranheza nas esculturas de bichos de pelúcia (em porcelana) e balão (em aço) de Koons: aos nossos abraços - que peças como Popples e Amore (1988), com seus braços abertos, convidam - elas seriam duras e frias, cheias de incômodas pontas agudas; um aperto com excesso de força poderia estilhaçá-las em cacos cortantes.

Os materiais lisos e impermeáveis das esculturas de Koons tornam literal e exageram outra característica dessa estética: "coisas cute têm superfícies limpas e sensuais que permanecem intatas e impenetradas (sugerindo, de fato, que não há nada dentro delas, que elas são exatamente o que se vê)" (HARRIS, 2000, p. 20). Entretanto, essa impenetrabilidade e clareza de formas das obras do artista, como já discutimos, sugere não apenas compreensibilidade imediata, mas também distância emocional e inacessibilidade - a frustração expressa por Rilke em relação aos brinquedos infantis: "só de você, alma da boneca, nunca pôde se dizer onde realmente estava" (1978, p. 48).

Koons, dessa forma, dramatiza a contradição embutida no cute, a complexidade oculta do seu jogo de poder, tão óbvia à primeira vista: o objeto aparentemente inocente pode nos enganar, escondendo malícia por trás de uma superfície ardilosamente simples.

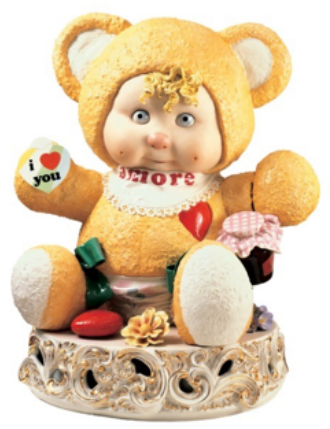

Fig.3. Amore (1988)

Fonte: jeffkoons.com

A contradição central do cute é ser uma estética de extremo artifício, "altamente maneirada" (HARRIS, 2000, p. 2), cujo efeito desejado é justamente uma aparência de inocência, de naturalidade, de total falta de ardil ou astúcia. A tensão entre ternura e desconfiança, portanto, é parte constitutiva da experiência estética do cute. Por parecer pequeno, carente, sincero, óbvio e deformado, o objeto cute nos impele a protegê-lo e carinhosamente molestá-lo, mantendo e reforçando a assimetria de poder que é constituinte da estética. Mas é justamente o seu caráter indefeso que nos causa suspeita: estamos sendo manipulados? A inocência e doçura escondem um plano maligno para nos desarmar, nos enganar e se aproveitar de nós? O cute, portanto, desperta nossos impulsos protetores, mas também a nossa agressividade e frustração, um amor inseparável do ódio, um desejo 
erótico de abraçar e destruir. "A rapidez e promiscuidade da resposta ao cute torna o impulso suspeito, prontamente ultrapassado por uma sensação raivosa de estar sendo explorado ou iludido" (ANGIER apud NGAI, 2012, p. 24).

As contradições do cute talvez ganhem sua melhor expressão, dentro da obra de Koons, na escultura de porcelana Amore, bizarro híbrido de boneco e ursinho de pelúcia (Fig. 3). Como Popples, a criatura tem braços abertos à nossa espera, membros subdesenvolvidos e um corpo globular e inchado, mas parece ainda mais incapaz: suas mãos são tocos semiesféricos sem dedos, e ela está sentada - de fato, suas pernas curtas parecem incapazes de sustentar o peso da sua cabeça monumental. Tal qual um bebê ela usa uma fralda e um babador. Complementando o aspecto grotesco, túmidas bochechas rosadas com barroquinhas furunculares, um nariz de cão e olhos azuis esbugalhados. A criatura professa seu amor triplamente: seu coração sai à superfície como um órgão externo, como se, impossibilitada de esconder suas emoções, ela as exibisse à flor da pele; seu babador contém a palavra italiana amore; e sua mão direita ostenta um adesivo com a frase " $I \vee$ you". A escultura se dirige pessoalmente ao espectador, mas sua declaração é vazia: o receptor da mensagem é qualquer um que estiver à sua frente, seu amor é indiscriminado e impessoal, constituindo-se assim como uma forma de indiferença. O excesso de signos fofos e a maneira exagerada e poliglota com que o bicho declara seu amor levanta a suspeita de manipulação e insinceridade, por um lado, e de carência excessiva, por outro; o afeto final que provoca, mais que ternura, é repulsa.

\section{A "fofura" da arte}

A primeira aparição da palavra cute registrada no Oxford English Dictionary data de 1857 e é exemplificada com a frase "“Que meiazinhas cute!', disse a mulher" (OXFORD ENGLISH DICTIONARY apud NGAI, 2012, p. 59). Já nessa primeira instância podemos observar duas características centrais da estética: seu endereçamento ao feminino (na forma como solicita impulsos maternais) e seu uso como adjetivo descritivo de mercadorias (no caso, um par de meias). O uso do termo cute alastrou-se à medida que o capital foi penetrando mais profundamente em mais esferas da vida. Em certo sentido, a ligação da estética da fofura com a mercadoria é publicitária:

O cute tornou-se essencial ao mercado, porque anunciantes aprenderam que consumidores irão "adotar" produtos que criam, amiúde somente em sua embalagem, uma aura de orfandade, ostracismo e melancolia, o desespero silencioso do cachorrinho perdido implorando para ser cuidado - isto é, para ser comprado. (HARRIS, 2000, p. 5)

O trecho de Harris acima citado ecoa fielmente algo há muito percebido por Walter Benjamin: "Se existisse aquela alma da mercadoria de que Marx por vezes fala, 
gracejando, ela seria a mais cheia de empatia que alguma vez se encontrou no reino das almas, porque teria de ver em cada um o comprador a cuja mão e casa se quer acolher." (BENJAMIN, 2015, p. 30-31)

Em um sentido mais profundo, entretanto, o cute não é apenas uma estética da compra, mas do consumo em todo o seu ciclo e, por isso, tem muito a dizer sobre a nossa relação com a mercadoria. Para Marx, toda mercadoria é fundamentalmente alienada; sua "alma" não está em seu corpo físico, palpável, mas em seu valor de troca, sua porção "mística" e imaterial, eternamente fora do nosso alcance.

Exatamente ao contrário da objetividade sensível e crua dos corpos das mercadorias, na objetividade de seu valor não está contido um único átomo de matéria natural. Por isso, pode-se virar e revirar uma mercadoria como se queira, e ela permanece inapreensível como coisa de valor. (MARX, 2013, p. 101)

O cute, em suas contradições, fala do desejo de vencer essa alienação, de usufruir das mercadorias de forma plena, de reestabelecer um regime imaginário de valor de uso puro, absoluto.

Retornando-nos a um mundo mais simples e sensual de uso e consumo doméstico, povoado exclusivamente de crianças e seus guardiões íntimos, o cute é a fantasia pastoral na qual, de alguma forma, o lado qualitativo da mercadoria como valor de uso, ou como produto de trabalho humano concreto, fenomenológico, pode ser extraído e assim "resgatado". Essa fantasia romântica, entretanto, requer força, uma obstinação da imaginação refletida, concebivelmente, nas distorções físicas da forma cute. [...] O desejo de acariciar e apertar o objeto que o cute provoca - ao ponto de esmagar ou danificar o objeto - pode ser lido como um esforço para "segurar" a mercadoria como um produto de trabalho humano concreto. (NGAl, 2012, p. 66)

O cute, portanto, apresenta uma imagem invertida do mundo capitalista, confessando, por meio de códigos, nossos desejos íntimos de uma realidade distinta e de relações diferentes; paradoxalmente, essa imagem nos é oferecida pelo próprio capitalismo, como promessa de felicidade via consumo, na qual acreditamos sem acreditar, dosando nossa entrega com nossa suspeita, nosso afeto fraco com nossa consciência da frivolidade das mercadorias fofas que nos interpelam.

O cute, uma adoração da mercadoria na qual eu quero ser tão íntimo ou estar tão fisicamente próximo dela o quanto possível, tem, portanto, algo de utópico, dirigindo-se ao desejo de habitar um mundo de uso concreto, qualitativo, em oposição a um mundo de troca abstrata. Em certo sentido, portanto, o fetichismo do cute é uma forma de resistir à lógica da mercantilização - predicada na ideia de "comensurabilidade absoluta de tudo" - tanto quanto é um reflexo sintomático dela. (NGAI, 2012, p. 12-13) 
Eis a surpreendente complexidade dos jogos de poder do cute: em sua impotência, ele propõe um modo de resistência à lógica da comodificação de todos os objetos e relações, mas o faz por meio de uma promessa de redenção do valor de uso das mercadorias que permanece espectral, fora do nosso alcance. Koons captura as ambiguidades do cute em objetos cujas formas são derivadas diretamente do universo da mercadoria, investigando a estética comercial do desejo e das promessas de plenitude, mas ressaltando seu caráter fugidio e ilusório em peças insistentemente superficiais.

As oscilações de poder entre sujeito estético e objeto cute ganham forma em Puppy (1992), escultura de flores vivas representando um filhote de West Highland Terrier com mais de 12 metros de altura (Fig. 4). A obra foi instalada pela primeira vez em Arolsen, cidade vizinha a Kassel (local em que acontecia a documenta IX), na Alemanha. Koons não foi convidado a exibir na mostra, e Puppy serviu como sua vingança e redenção - uma demonstração de poderio artístico capaz de rivalizar com uma das exposições de arte mais prestigiosas do mundo. Seu sucesso foi absoluto: o crítico Peter Schjeldahl, escrevendo para a revista Art in America, afirmou que a nona edição da mostra seria lembrada como "a documenta do cão", mesmo a escultura de Koons estando fora da exposição.

\begin{abstract}
Desgostar dela, estando em sua presença, era impossível. [...] Noblesse oblige materializada, Puppy radiava a benevolência do privilégio, condescendendo no sentido positivo, do Velho Mundo - a pessoas de todos os gostos e classes concebíveis, em um pacote completo oferecendo sofisticação estética para os sofisticados, alegria inocente para os ingênuos e diversão vulgar para os vulgares. (SCHJELDAHL, 1992, p. 89)
\end{abstract}

Tão inofensivo à primeira vista, Puppy é descrito aqui como uma poderosa máquina de consenso, capaz de dobrar os joelhos em submissão - docemente - a todos os que se colocam à sua frente. Parte significativa desse efeito é lograda por meio da sua escala: diante do gigantesco filhote, o espectador é diminuído; somos nós que cabemos em suas patas, e é ele que poderia, hipoteticamente, nos proteger ou esmagar. Também somos vítimas de outra propriedade-chave do cute: seu apelo mimético, expresso na "compulsão em imitar as propriedades 'fofas' do objeto em nossa fala" (NGAI, 2012, p. 67). Diante de um bebê, por exemplo, tendemos a emitir sons de bebê e falar "como bebês". Ao solicitar nossa empatia e identificação, o cute nos reduz a seres balbuciantes, incapazes, assim como o objeto fofinho, de formular um discurso conceitual coerente, pondo em questão, dessa forma, nossa posição dominante em relação a ele. Koons inverte os vetores da relação de poder entre sujeito e objeto cute: somos nós que parecemos impotentes e indefesos diante da magnitude da obra e da proeza técnica do artista em produzi-la e incapazes de resistir a seus apelos adocicados ou criticá-los de forma fria e racional. 


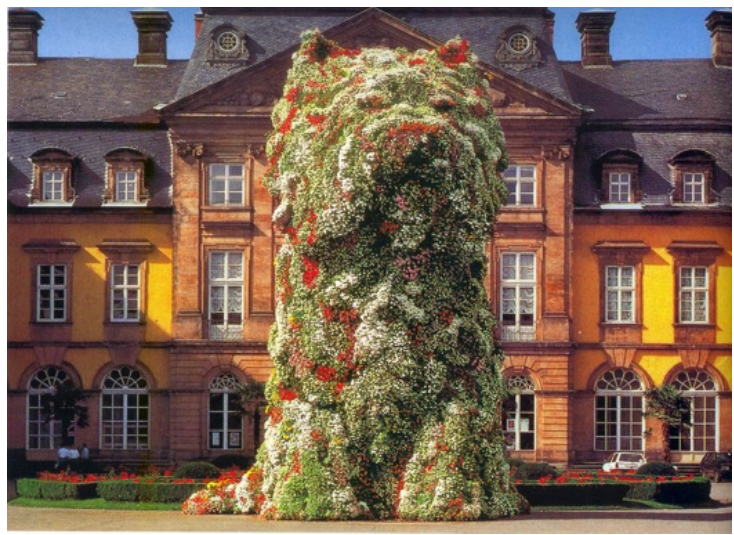

Fig.4. Puppy (1992).

Fonte: jeffkoons.com

Da lição de Puppy podemos extrair algumas conclusões sobre a obra de Koons em geral: se os temas banais despertam desprezo por parte do establishment artístico, a dificuldade técnica, a complexidade e alto custo do processo de produção e os altíssimos preços de venda comandam, à força, respeito e admiração. A popularidade do artista entre megacolecionadores e público e sua presença massiva nos meios de comunicação o tornam impossível de ser ignorado. O ressentimento e ódio que Koons - um artista à primeira vista tão ingênuo - provoca em certa parcela do mundo artístico só pode ser medido em relação à sua fama e sucesso comercial inquestionáveis. Jeff Koons é talvez o emblema maior do recente boom das artes visuais, da transformação de um campo relativamente insular em uma indústria cultural global, inflada por fluxos de capital internacional e graúdos investimentos corporativos, recordes milionários em casas de leilão e museus de arquitetura espetacular bancados por multinacionais. Seus bichinhos e brinquedos, agigantados e brilhantes como joias monumentais, são a face atraente desse novo sistema que parece cada vez mais distante da autodeclarada autonomia modernista. É simbólico, portanto, que Puppy tenha ganhado um lar permanente em frente ao museu Guggenheim de Bilbao, outro ícone da era de museus multinacionais e da arte como chamariz para turistas e investidores.

Tendo a relação entre o cute e a mercadoria em mente, Ngai argumenta que o conceito pode ser mobilizado, surpreendentemente, para uma melhor compreensão da Teoria Estética, de Theodor Adorno, livro inconcluso que viria a sintetizar as reflexões do filósofo alemão sobre a arte na sociedade burguesa. Para a autora, o tema da impotência da arte no regime capitalista, da sua completa falta de poder em uma realidade social pautada pela comodificação de tudo, é central ao pensamento adorniano que enxerga em toda declaração de auto-importância da arte uma marca do ridículo: "[a arte] tende para um movimento inerte e vão; teleologicamente visa um hobby infantil. [...] A sombra 
do radicalismo autárquico da arte é o seu caráter inofensivo" (ADORNO, 2008, p. 42). O projeto de autonomia do campo artístico se concretiza, na modernidade, simultaneamente à ascensão da burguesia como classe dominante e, portanto, é um fenômeno histórico que só pode ser compreendido em sua relação com a sociedade burguesa, relação pautada pela sua impotência e superfluidade.

O projeto da arte autônoma torna-se, crescentemente, uma meditação carregada de culpa sobre a sua própria impotência social. É como se no momento em que a arte finalmente alcançasse distância da sociedade ela não mais tivesse a opção de deixar em paz a questão social da sua relação com a sociedade. (NGAl, 2012, p. 105)

Reificada, a obra de arte autônoma assume características do objeto cute: "sua mudez, ou resistência mimética à fala comunicativa ou conceitual, sua relação oculta com a violência, sua qualidade de brinquedo, seu fator kitsch e seu ridículo" (Ibidem, p. 106). O giro dialético operado por Adorno é afirmar que é precisamente essa fraqueza, essa fofura da arte que é a sua força, na medida em que é um ato de resistência contra o poder do mercado e do valor de troca que julga todas as coisas por valores abstratos de outra ordem: o reino da completa heteronomia. Daí a defesa adorniana da autonomia da arte e da sua reificação como " 'veneno' homeopático que a arte precisa engolir 'para permitir à estética uma existência continuada em um mundo plenamente reificado' " (NGAl, 2012, p. 106):

As obras modernas abandonam-se mimeticamente à reificação [...]. Sem a adição do veneno, virtualmente a negação do vivo, o protesto da arte contra a opressão da civilização seria uma consolação impotente (ADORNO, 2008, p. 154)

A arte só se mantém em vida através da sua força de resistência; se não se reifica, torna-se mercadoria. O seu contributo para a sociedade não é a sua comunicação com ela, mas algo de muito mediatizado, uma resistência, em que a evolução social se reproduz em virtude do desenvolvimento intra-estético, sem ser a sua imitação (Ibidem, p. 254).

Durante todo o processo da modernidade ocidental, o campo das artes veio a ser definido como um espaço de exceção, uma autarquia com regras próprias, irredutível aos imperativos do mercado que colonizava tudo ao redor. A autonomia da arte sempre foi mais uma idealização que sublimava as práticas econômicas do campo do que uma realidade, mas em sua lógica interna a ideologia da arte salvaguardou certos valores de resistência valiosos. Em um momento em que o campo das artes visuais parece estar completando a transição de um regime de "autonomia relativa" a um de "heteronomia relativa" (GRAW, 2009, p. 142-147), em que o campo se aproxima das indústrias do entretenimento e dos bens de luxo (com seus princípios de lucro em maior ou menor 
medida embutidos na própria lógica criativa²), cabe questionar se ainda é possível pensar em termos de autonomia resistente. O campo das artes, enquanto indústria cultural cada vez mais poderosa, parece sair fortalecido nessa nova situação; ao perder o seu caráter cute de distância da lógica da heteronomia, entretanto, ele se enfraquece. Sua capacidade de resistência - a sua impotência potente - é diminuída. O kitsch monumentalizado de Koons funciona como metáfora extremamente apta para essa condição da arte no século 21: simultaneamente inflada e contida, anabolizada e trivial, vitoriosa e fragilizada. Que essa reflexão esteja embutida, mesmo que indiretamente, na própria forma das obras de Koons é um paradoxo que demonstra que a arte, ainda assim, permanece capaz de provocar, pela via da sensibilidade, um estímulo intelectual vital, pondo em dúvida sua possibilidade de existência na atualidade ao mesmo tempo em que protesta pela sua continuada relevância.

Pedro Pinheiro Neves é doutorando em Comunicação na Universidade Federal do Rio de Janeiro. Mestre em Comunicação pela Universidade Federal de Pernambuco.

pedro_pneves@hotmail.com

\section{Referências}

ADORNO, T. Teoria estética. Lisboa: Edições 70, 2008.

AGAMBEN, G. Stanzas. Minneapolis: University of Minnesota Press, 1993.

ARIÈS, P. Centuries of childhood. New York: Alfred A. Knopf, 1962.

BENJAMIN, W. Baudelaire e a modernidade. Belo Horizonte: Autêntica, 2015.

DANTO, A. After the end of art. Princeton: Princeton University Press, 1997.

FOSTER, H. El retorno de lo real. Madrid: Ediciones Akal, 2001.

.Design and crime. London: Verso, 2002.

GRAW, I. High price: art between the market and celebrity culture. Berlin: Sternberg Press, 2009.

HARRIS, D. Cute, quaint, hungry and romantic. New York: Basic Books, 2000.

JAMESON, F. A virada cultural. Rio de Janeiro: Civilização Brasileira, 2006.

MARX, K. Early writings. London: Penguin Classics, 1992.

O capital - livro 1. São Paulo: Boitempo, 2013.

NGAI, S. Our aesthetic categories: zany, cute, interesting. Cambridge: Harvard University Press, 2012.

RILKE, R. M. Some reflections on dolls. In: Where silence reigns. New York: New Directions, 1978.

2 Vide a obra de Takashi Murakami, em que a ideia da peça única, caríssima, e suas reproduções mais baratas para atingir uma faixa de público mais ampla, faz parte do próprio conceito. 
SCHJELDAHL, P. The Documenta of the dog. Art in America, New York, set. 1992, p. 89-97.

STALLYBRASS, P. O casaco de Marx. Belo Horizonte: Autêntica, 2000.

Texto recebido em 1 de julho de2017

e aprovado em 20 de janeiro de 2018. 